\title{
A PROTEÇÃO DE DIREITOS SOCIAIS DOS TRANSGÊNEROS: IMPACTOS DA DECISÃO DO SUPREMO TRIBUNAL FEDERAL NA AÇÃO DIRETA DE INCONSTITUCIONALIDADE N. 4.275 NO BRASIL
}

\author{
PROTECTION OF SOCIAL RIGHTS OF TRANSGENDER PERSONS: \\ THE IMPACTS OF THE SENTENCE OF THE FEDERAL SUPREME COURT IN \\ THE DIRECT ACTION OF UNCONSTITUTIONALITY 4,275 IN BRAZIL
}

\author{
Beatriz Falcão Rios* \\ Tarik Vervloet Fontes ${ }^{* *}$ \\ Fábio da Silva Santos***
}

\begin{abstract}
Resumo:
A questão dos direitos sociais dos transgêneros brasileiros ganha destaque no contexto de proteção à minorias. Principalmente, a partir do momento em que o Supremo Tribunal Federal julgou procedente no dia $1^{\circ}$ de março de 2018 a Ação Direta de Inconstitucionalidade n. 4.275 para dar interpretação conforme a Constituição e o Pacto de São José da Costa Rica ao art. 58 da Lei n. 6.015/73, permitindo aos transgêneros, que são aqueles que não se identificam com o seu gênero biológico, alterarem no cartório (via administrativa) o prenome e gênero diretamente no registro civil e sem a obrigatoriedade de ter realizado a cirurgia de transgenitalização. Por meio de uma pesquisa exploratória, com referenciais teóricos e um estudo realizado sobre as histórias de vida, será possível conhecer os impactos positivos e negativos dessa decisão, bem como, os enfrentamentos do dia a dia da população trans. Pode-se inferir que houve um avanço na história do Brasil com a Ação Direta de Inconstitucionalidade n. 4.275, pois apesar dos impactos negativos mencionados é perceptível que já estamos um passo à frente da desconstrução da cultura transfóbica.
\end{abstract}

Palavras-chave: Direitos Sociais. Transgênero. Ação Direta de Inconstitucionalidade n. 4.275 .

\footnotetext{
* Advogada. OAB/Bahia. Bacharela em Direito pelo Centro Universitário Ruy Barbosa (UniRuy) - Wyden Educacional. E-mail: beatrizfalcao16@hotmail.com.

** Advogado OAB/Bahia. Bacharel em Direito e Especialista em Direito Processual Civil pela Pontifícia Universidade Católica (PUC) de São Paulo. Mestrado em Direito Tributário pela Fundação Getúlio Vargas (FGV - São Paulo). E-mail: tarikfontes@hotmail.com.

*** Doutorando em Direito Público pela Universidade Federal da Bahia (UFBA). Pesquisador do Centro e Grupo de Pesquisa em Proteção Internacional de Minorias (CEPIM) - Faculdade de Direito - Universidade de São Paulo - USP. Mestrado e Doutorado pela Universidade Salvador (UNIFACS) e Bolsista CAPES. Bacharel em Direito pela Universidade Estadual de Santa Cruz (UESC), Especialista em Direito Público e em Docência do Ensino Superior. Membro do Grupo de Pesquisa em Análise Econômica do Direito (UFBA), Educação e Desenvolvimento e em Cidades, Urbanismo e Urbanidades. Pesquisador do Instituto Geográfico e Histórico da Bahia. Líder do Grupo de Pesquisa em Direitos Humanos, Violência e Minorias Invisíveis (UNIRUY). Professor (Cursos de Graduação e Pós-Graduação) de Direito, Metodologia Científica e Pesquisa Jurídica (Centro Universitário Ruy Barbosa - UNIRUY Wyden Educacional; Faculdade Nobre de Feira de Santana - FAN, Unidade de Ensino Superior de Feira de Santana - UNEF, Universidade Católica do Salvador - UCSAL, Faculdade de Tecnologia e Ciências - FTC). E-mail: fabiosantosdireito@gmail. com.
} 


\begin{abstract}
:
The issue of social rights of Brazilian transgender persons is highlighted in the context of protecting minorities. Mainly, from the moment the Supreme Federal Court judged on March 1, 2018 the Direct Action of Unconstitutionality No. 4,275 to interpret article 58 of Law No. 6,015/73 according to the Brazilian Constitution and the Pact of San José, Costa Rica, allowing transgender persons, who are those who do not identify with their biological gender, to change the first name and gender in the registry office (administrative route) directly and without the obligation to have undergone transgenitalization surgery. Through an exploratory research, with theoretical references and a study carried out on life histories, it will be possible to know the positive and negative impacts of this sentence, as well as the daily confrontations of the transgender people. It can be inferred that there was an advance in the history of Brazil with the Direct Action of Unconstitutionality No. 4,275 , because despite its negative impacts mentioned, this sentence was one step towards the deconstruction of the transphobic culture.
\end{abstract}

Keywords: Social rights. Transgender. Direct Action of Unconstitutionality No. 4,275 .

\title{
1. Introdução
}

Este artigo aborda sobre os impactos da decisão do Supremo Tribunal Federal na Ação Direta de Inconstitucionalidade n. 4.275 no Brasil: estudo sobre a história de vida dos transgêneros. Com isso, a problemática dessa escrita consistirá em discorrer sobre quais impactos foram incrementados após a procedência da decisão supramencionada no Brasil, que garantiram a dignidade da pessoa humana.

A pesquisa deu-se de forma qualitativa com a utilização da entrevista semiestruturada e a abordagem metodológica utilizada foi de pesquisa participante. Antevê-se à pesquisa participante, à de cunho bibliográfico com leituras de artigos, periódicos e livros dos autores citados.

O objetivo geral baseia-se em demonstrar os impactos na vida dos transgêneros após a decisão do Supremo Tribunal Federal na Ação Direta de Inconstitucionalidade n. 4.275 no Brasil. De suma importância destacar que foi uma revolução histórica para o Brasil, que trouxe impactos para a população trans, sendo um grande avanço para iniciarmos a desconstrução do preconceito e para garantir a reafirmação de direitos existentes.

Na primeira parte terá um breve resumo sobre a tramitação da decisão no Supremo Tribunal Federal no julgamento da Ação Direta de Inconstitucionalidade n. 4.275, que permitiu aos transgêneros a alteração no registro civil do seu prenome e gênero, sendo essa alteração feita diretamente no cartório (via administrativa) e sem a obrigatoriedade de ter realizado a cirurgia de transgenitalização. 
Na segunda parte será abordado sobre a identidade de gênero e questões controversas, dentro dessa escrita será explicado quem são os transgêneros, a divergência entre transexual e travesti, a equiparação que é feita erroneamente entre a travesti e drag queen, os outros tipos de identidade de gênero, a diferença entre orientação sexual e identidade de gênero e os questionamentos feitos pela sociedade "transgênero é homossexual?" e "como devo tratar essa pessoa? Ele ou ela?", por último, não menos importante, será explicado sobre o sufixo -ismo.

A terceira parte versa sobre a intolerância e exclusão dos transgêneros no Brasil, trazendo informações acerca da média de transgêneros existentes no país, sobre o número de mortes das pessoas trans, a exclusão do mercado de trabalho, o bullying sofrido por essas pessoas, a dificuldade do acesso à justiça, à saúde e educação, bem como, todas essas problemáticas que são enfrentadas diariamente por eles.

$\mathrm{Na}$ quarta parte será discorrido rapidamente sobre o princípio jurídico constitucional da dignidade da pessoa humana dentro do contexto dos transgêneros. Cabe destacar que esse princípio é importante pelo fato dele ser inviolável e por garantir a todos os seres humanos os direitos fundamentais, podendo ser direitos políticos ou morais.

$\mathrm{Na}$ quinta e última parte será o resultado das pesquisas, tendo um quadro específico com a caracterização dos entrevistados, porém com nomes fictícios por ética do trabalho. Essa pesquisa foi feita com três homens trans, no qual relatam sobre todo o contexto de suas histórias, sobre a vida pessoal, as vivências, os enfrentamentos do dia a dia e o quanto essa decisão do Supremo Tribunal Federal na Ação Direta de Inconstitucionalidade n. 4.275 impactou as suas vidas.

Os transgêneros sofrem diariamente com a falta de conhecimento das pessoas, a intolerância que as regem e a falta de compreensão com a identidade de gênero. A ADI n. 4.275 veio com o intuito de reafirmar o direito da população trans e para dar-lhes tranquilidade ao acessar locais que precisam do documento de identificação.

2. Resumo do julgamento da decisão do Supremo Tribunal Federal na Ação Direta de Inconstitucionalidade n. 4.275

A Procuradoria-Geral da República propôs Ação Direta de Inconstitucionalidade em face do Presidente da República, Congresso Nacional, sendo originada no Distrito Federal, foi fundamentada com base na Constituição da República Federativa do Brasil de 1988, arts. 102, inciso I, alínea "a", e 103, inciso VI, e dos dispositivos da Lei n. 9.868/99, que teve entrada no STF em 21/07/2009.

A petição inicial foi instruída acompanhada de cópia de representações formuladas pela ABGLT - Associação Brasileira de Gays, Lésbicas, Bissexuais, Travestis e Transsexuais, assim como, julgados que não reconhecerem o direito pleiteado na Ação 
Direta de Inconstitucionalidade (ADI) - n. 4.275, como uma forma de reivindicação de direitos que estão sendo negados.

A ação em questão tem como finalidade dar interpretação de acordo com a Constituição da República Federativa do Brasil de 1988 e o Pacto de São José da Costa Rica ao art. 58 da Lei n. 6.015/1973, que aborda acerca dos registros públicos, na perspectiva de autorizar a alteração do prenome e gênero no registro civil mediante averbação no registro original, independente da cirurgia de transgenitalização.

Contudo, o Supremo Tribunal Federal (STF) julgou ser possível a alteração do gênero e prenome no assento de registro civil mesmo sem a realização da cirurgia de redesignação de sexo, o trâmite durou cerca de nove anos, bastante moroso. A decisão final do Supremo Tribunal Federal (STF) no julgamento da Ação Direta de Inconstitucionalidade (ADI) n. 4.275 ocorreu no dia $1^{\circ}$ de março de 2018. Conforme relatoria do Ministro Marco Aurélio:

Decisão: O Tribunal, por maioria, vencidos, em parte, os Ministros Marco Aurélio e, em menor extensão, os Ministros Alexandre de Moraes, Ricardo Lewandowski e Gilmar Mendes, julgou procedente a ação para dar interpretação conforme a Constituição e o Pacto de São José da Costa Rica ao art. 58 da Lei 6.015/73, de modo a reconhecer aos transgêneros que assim o desejarem, independentemente da cirurgia de transgenitalização, ou da realização de tratamentos hormonais ou patologizantes, o direito à substituição de prenome e sexo diretamente no registro civil. Impedido o Ministro Dias Toffoli. Redator para o acórdão o Ministro Edson Fachin. Presidiu o julgamento a Ministra Cármen Lúcia. Plenário, 1.3.2018.

3. Identidade de gênero e questões controversas

3.1. A definição de gênero

De início, cabe a definição de gênero, para podermos seguir adiante. Temos que, o “gênero é uma questão de identidade, ‘transgênero’ é a terminologia mais genérica, na qual se enquadram o transexual e o travesti. Em comum, têm o fato de que ambos vivenciam um gênero em desconformidade com o seu sexo biológico". (BARBOZA, 2012 apud BATISTA, 2019, p. 1).

Então, podemos concluir que transgênero é expressão/identidade de gênero da pessoa, digamos que é o termo utilizado para indicar os que se identificam a partir de como se percebem e como se sentem, bem como, a forma em que desejam ser reconhecidos pelas pessoas, podendo ser mulher, homem, os dois ou até mesmo nenhum dos gêneros. 
De maneira mais compreensível, é o indivíduo que se identifica com o gênero diferente daquele do seu nascimento, ou seja, o biológico.

Lanz, 2011 apud Nery (2011, p. 230) menciona que:

Pessoa "trans" é aquela que está em permanente
"transformação", disposta a "trans-por" todos os
obstáculos. É aquela pessoa que "trans-gride" regras e
padrões de conduta, "transmitindo" à sociedade, de forma
absolutamente "trans-parente", novas ou inexploradas
possibilidades de realização. Pessoa "trans" é aquela que
"trans-cende" a si mesma, tentando expressar ao mundo a
pessoa que ela realmente é em vez da pessoa que o mundo
acha que ela deveria ser.

\subsection{A travesti e o transexual}

A travesti nasce com o gênero masculino e se identifica com a figura da mulher, tanto que se vestem com roupas, sapatos e acessórios femininos. Muitas delas não fazem a cirurgia de transgenitalização, porém algumas colocam silicone nos seios. "São travestis as pessoas que vivenciam papéis de gênero feminino, mas não se reconhecem como homens ou como mulheres, mas como membros de um terceiro gênero ou de um não-gênero". (JESUS, 2012, p. 17).

O transexual pode ser mulher ou homem, pois são aqueles que se identificam psicologicamente com o sexo oposto, mas não necessariamente fazem a cirurgia de redesignação sexual, alguns fazem o tratamento hormonal para ficar com a aparência desejada e para alterar a voz. Os que optarem pela cirurgia de transgenitalização precisará ter acompanhamento durante dois anos por uma equipe multidisciplinar, o que é de suma importância, pois há dados que confirmam o suicídio após procedimento cirúrgico, provavelmente decorrente de alguma não aceitação e/ou mau acompanhamento.

Ramsey (1988, p. 32) afirma que:

$\mathrm{Na}$ minha experiência, transexualidade - ao contrário de um simples distúrbio de identidade de gênero - não é um fenômeno passageiro. Poderia antes ser descrito como "imutável na maioria das instâncias". (É também extremamente raro que psicoses se apresentem como transexualidade aparente.) O processo transexual - a jornada que começa com uma terapia e vestir-se como o outro sexo, passa por tratamento hormonal e termina em cirurgia - não é um capricho passageiro. É a busca consistente de integração física, emocional, social, espiritual e sexual, conquistada a enormes penas pessoais. 
Entende-se que a divergência entre travestis e transexuais está voltada, principalmente, para a forma como se sentem com o seu gênero biológico durante a vida. As travestis não se sentem desconfortáveis com o seu órgão sexual, tendo em vista que escolhem não realizar a cirurgia de redesignação sexual, mesmo mudando o tom da voz e a sua aparência física. Os transexuais podem ser homens ou mulheres, são pessoas psicologicamente insatisfeitas com o seu gênero de nascimento e com os padrões que a sociedade impõe diante disso.

\subsection{Diferenças entre drag queen e travesti}

Meritório o destaque de que muitas pessoas equiparam drag queen com travestis, porém, são diferentes, inclusive a drag queen não é uma identidade de gênero, "são homens que se vestem como mulher de maneira caricata com o intuito de realizar performances artísticas, que incluem canto e dança, geralmente em festas e casas noturnas". (LEITE, 2017b, p. 4).

A travesti tem a identidade feminina na vida pessoal. Já a drag queen, é uma expressão artística de homens que se transformam com vestimentas, acessórios e maquiagens para atuar, desfilar ou cantar, ou seja, são personagens que ao final do show ou evento voltam para a sua aparência física original.

\subsection{Outros tipos de identidade de gênero}

Existem outros tipos de identidade de gênero, o intersexual, que vulgarmente era chamado como "pessoa hermafrodita". $\mathrm{O}$ "intersexo (quando há presença de determinantes tanto masculinos quanto femininos)". (LEITE, 2017b, p. 1).

O outro é o gênero flutuante, que é a pessoa que não estabelece uma identidade fixa, ela pode passar uma época da vida adotando a aparência feminina e depois de um tempo mudar para a aparência masculina ou vice e versa. Queer é a pessoa que não se reconhece como homem e nem como mulher, não se rotula como heterossexual ou homossexual e para além da aparência física e sexualidade, o queer questiona e discute sobre o conservadorismo da sociedade com os papéis impostos para cada gênero.

Existe também o questionamento dos gêneros binário x não binário. O que nos foi ensinado é que binário é separação entre "mulher" e "homem", já o não binário é aquela pessoa "cuja identidade de gênero não é nem masculina nem feminina, está entre os sexos ou é uma combinação de gêneros". (LEITE, 2017b, p. 3). 


\title{
3.5. Identidade de gênero x orientação sexual
}

Outra temática que merece destaque é a diferença entre identidade de gênero x orientação sexual, que são duas particularidades diferentes de todo ser humano. A identidade de gênero, como já foi mencionada, é a forma que a pessoa se reconhece psicologicamente e fisicamente (transgênero x cisgênero).

Já a orientação sexual refere-se ao gênero que a pessoa sente atração sentimental e/ou com quem se relaciona, sexualmente ou não (heterossexual, homossexual, bissexual ou assexual). O heterossexual é a pessoa que tem atração apenas pelo gênero oposto. Homossexual ou homoafetivo é quem tem atração somente pelo mesmo gênero. Bissexual ou biafetivo são pessoas que se atraem pelo mesmo gênero e também pelo gênero oposto. Assexual é aquela pessoa que não sente atração por nenhum gênero.

Junqueira, 2017 apud Arpini (2017, p. 1) afirma que:

\begin{abstract}
A orientação sexual irá fazer com que a pessoa busque relacionamentos afetivos-sexuais com pessoas do mesmo sexo (homossexual), sexo oposto (héterossexual) e ambos (bissexual). Já na identidade de gênero diz respeito a como a pessoa se sente, se do gênero feminino ou masculino.
\end{abstract}

\subsection{Transgênero é homossexual?}

Um questionamento que é feito por algumas pessoas da sociedade: “Transgênero é homossexual?”, não necessariamente. Exemplo, uma mulher (definindo biologicamente) ao adotar o gênero masculino (gênero psicológico) e que sente atração e/ou se relaciona apenas com mulheres será considerada heterossexual, já que ela se reconhece como sendo do gênero masculino.

\subsection{Como devo tratar essa pessoa?}

Outra questão de repercussão na sociedade: "Como devo tratar essa pessoa? Ele ou ela?" Via de regra, o tratamento deve ser feito conforme o gênero que a pessoa se identifica. Para travestis, o correto é utilizar o artigo "a", já que estamos nos referindo à mulher transgênero. Já transexuais depende se o gênero que a pessoa se reconhece é o feminino ou masculino. Alguns transgêneros não se importam com o uso do "o" ou "a", "ele" ou "ela", para se referirem a eles, mas geralmente se incomodam com a incompreensão das pessoas. Na verdade, não existe uma resposta concreta para esse questionamento, faz parte da individualidade de cada ser humano, para simplificar, é só perguntar como a pessoa gosta de ser tratada, o importante é respeitar. 


\subsection{O sufixo -ismo}

Por último, e não menos importante, o sufixo -ismo não deve ser utilizado para falar de homossexuais, tendo em vista que dá ideia de patologia. "Homossexualismo" é um termo que não deve ser utilizado, bem como deixou de existir desde 1993, ano em que as relações homoafetivas deixaram de ser consideradas como uma doença, de acordo com a Classificação Internacional de Doenças (CID). O termo que deve ser utilizado é homossexualidade, já que o sufixo -dade significa "vivência ou prática".

Oficialmente, no dia 20 de maio de 2019, a transexualidade deixou de ser considerada um transtorno mental pela Organização Mundial da Saúde (OMS). A informação segue de que cada país terá até o dia $1^{\circ}$ de janeiro de 2022 para fazer a adaptação da nova norma da CID. Conforme Dias (2019, p. 1) cita:

Após 28 anos na categoria de transtornos mentais, a transexualidade não poderá mais ser classificada como doença. Por mais que a novidade já tenha sido divulgada antes, o caso só foi oficializado nesta segunda-feira (20), durante a $72^{\circ}$ Assembleia Mundial da Saúde, em Genebra.

\section{Intolerância e exclusão dos transgêneros no brasil}

No Brasil não há levantamentos exatos sobre a quantidade de transexuais existentes, pois a maioria dos dados encontrados refere-se ao geral, que é a população LGBTs, mas em estudos realizados é possível ter uma base.

Leite, (2017a, p. 2) informa que:

Embora não haja levantamentos precisos sobre quantos transexuais existem no Brasil, estudos mencionados em junho passado pela revista especializada The Lancet apontam que entre $0,4 \%$ e $1,3 \%$ das pessoas com mais de 15 anos não se identifica com seu sexo biológico, o que permite estimar em pelo menos 25 milhões o total de trans no mundo. Utilizando esses índices para a população brasileira, é possível afirmar que há entre 752 mil e 2,4 milhões de trans vivendo no país.

É perceptível que os transgêneros não contam com uma legislação que os protejam, vivem à margem da sociedade, lutando a favor da sua identidade de gênero e orientação sexual. Os trans passam, diariamente, por riscos constantes de violência física, psicológica e todas as diversas formas de violências existentes, muitas vezes são excluídos do mercado de trabalho, enfrentam o bullying nas escolas e universidades, encontram dificuldades para ter acesso à saúde e à justiça, passam por conflito familiar que os levam 
ao sofrimento de não serem aceitos, por serem questionados, excluídos e até são expulsos de casa.

O Brasil se encontra posicionado entre os países que mais mata trans no mundo, conforme pesquisa realizada em 2016. Cunha $(2017$, p. 1) afirma:

O Brasil matou ao menos 868 travestis e transexuais nos últimos oito anos, o que o deixa, disparado, no topo do ranking de países com mais registros de homicídios de pessoas transgêneras. (O dado, publicado pela ONG Transgender Europe (TGEu) em novembro de 2016, é assustador, mas não representa novidade para essa parcela quase invisível da sociedade brasileira, que precisa resistir a uma rotina de exclusão e violência.

O número é exorbitante, essa análise é feita através do total de mortes de transgêneros para cada milhão de habitantes, sendo que o Brasil está em quarta posição. Cunha (2017, p. 1) relata que:

Segundo o relatório da TGEu, o país registra, em números absolutos, mais que o triplo de assassinatos do segundo colocado, o México, onde foram contabilizadas 256 mortes entre janeiro de 2008 e julho de 2016. Em números relativos, quando se olha o total de assassinatos de trans para cada milhão de habitantes, o Brasil fica em quarto lugar, atrás apenas de Honduras, Guiana e El Salvador.

Vale a ressalva de que esses números postos são apenas os registrados, ou seja, são mascarados, pois o índice, sem dúvida, é muito maior. Isso ocorre devido à dificuldade que os países têm para registrar as ocorrências dos crimes, muitos são registrados de maneira errada, como por exemplo, "mulher vestida de homem".

Segundo Cunha, (2017, p. 3):

A pesquisa da TGEu aponta algumas razões para que esse cenário de violência se apresente no Brasil e em outros países da América Latina, região que reúne $78 \%$ dos homicídios relatados no documento. Entre os motivos, estão grandes níveis de violência no contexto histórico (colonialismo, escravidão, ditaduras), alta vulnerabilidade de transexuais na prostituição e a falha do Estado em prevenir e investigar esses crimes.

Os transgêneros enfrentam muitas situações adversas, como o bullying nas escolas e universidades que faz com que ocorra a evasão dos transgêneros desses lugares, refletindo por toda a vida deles. Outro exemplo é o mercado de trabalho que fica mais difícil, pois se já existem poucas oportunidades para quem tem ensino superior completo, imagina pra quem nem sequer conseguiu terminar o ensino fundamental e/ou ensino médio e é aí que eles recorrem para o único meio de sobrevivência possível, a prostituição. 
O acesso à saúde para a população transgênero é extremamente complicada, primeiro pelo fato de que alguns transgêneros ainda não conseguiram alterar a sua identidade de gênero e prenome no documento de identificação, o que gera um desconforto, constrangimento e até mesmo conflito nesses ambientes de acesso à saúde, pois os mesmos precisam identificar-se ao entrar. Outro fato gerador da falta de acesso à saúde é a escassez de profissionais qualificados para atender e fazer os procedimentos desejados pelos trans, sem contar que na rede pública, por si só, já é um desafio, tendo em vista a falta de serviço e profissionais em números suficientes.

No Brasil, até 1997, a cirurgia de transgenitalização (redesignação do sexo masculino para o feminino ou do feminino para o masculino) era proibida. Em 2008 o Sistema Único de Saúde (SUS) liberou o procedimento para realização da mudança do sexo com os acompanhamentos necessários.

Leite (2017a, p. 2) informa que:

Só existem ambulatórios especializados em 11 cidades. Já as instituições habilitadas pelo Ministério da Saúde para realizar a cirurgia de adequação sexual são quatro, localizadas em Porto Alegre, Recife, Rio de Janeiro e São Paulo - até recentemente, o procedimento era realizado também no Hospital das Clínicas da Universidade Federal de Goiás (UFG), mas o serviço foi interrompido. Os dados mais recentes do governo federal mostram que, entre 2008 e 2014, apenas 243 procedimentos cirúrgicos foram realizados.

Vale lembrar, que muitos fazem todo o procedimento ou, pelo menos, metade dele, clandestinamente, sem nenhum acompanhamento, colocando a sua própria vida em risco, devido ao difícil acesso à saúde, até mesmo quando o procedimento é particular.

Devido a todas essas situações, os transgêneros morrem muito cedo, muitos cometem suicídio, devido à discriminação que sofrem, a incompreensão das pessoas e as diversas formas de violência que passam, fazendo com que seja um dos grupos mais vulneráveis do mundo.

Alguns estudos apontam que cerca de 60\% dos trans em alguns países adquirem depressão, esse número assusta e chama atenção para a importância da criação de políticas públicas voltadas para essa população. Nota-se que alguns que não sofrem depressão ou algum tipo de síndrome do pânico é porque tem o apoio dos familiares, amigos, profissionais da saúde e também porque conseguiram alterar toda a sua documentação para viverem conforme a sua identidade de gênero.

Não se pode esquecer o alto índice dos trans assassinados. O Instituto Brasileiro de Geografia e Estatística (IBGE), em pesquisa feita no final do ano de 2016, 
tem como estimativa de vida dos trans no Brasil, 35 anos, enquanto o restante da população tem a expectativa de vida de 75,5 anos, em média; situação caótica.

$\mathrm{O}$ acesso à justiça para os transgêneros deixa a desejar, não há legislação que os protejam, porém existe uma Ação Direta de Inconstitucionalidade por Omissão e um Mandado de Injunção em trâmite no STF em busca da criminalização da LGBTfobia, se o julgado for positivo vai ser mais uma revolução histórica no nosso país. No mais, cabe mencionar o tema desse artigo, que trata da decisão do Supremo Tribunal Federal na Ação Direta de Inconstitucionalidade n. 4.275, que teve como escopo a autorização da alteração do prenome e gênero pela via administrativa (cartório) no qual obteve êxito.

Antes dessa ADI n. 4.275 já existia o Decreto n. 8.727, de 28 de abril de 2016, que permitia a utilização do nome social e reconhecia a identidade de gênero das pessoas travestis e transexuais (transgêneros) na esfera da administração pública federal direta, autárquica e fundacional. O Sistema Único de Saúde (SUS) desde 2008 faz a cirurgia de transgenitalização com os devidos acompanhamentos para a população transgêneros. Sabemos que esses amparos são de suma importância, porém não são suficientes, faltam políticas de inclusão no mercado de trabalho, investigação dos crimes cometidos em desfavor dos transgêneros e providências que tenham resultados positivos para que a população trans não morra tão cedo.

\section{Bortoni (2017, p. 5) cita que:}

$\mathrm{O}$ preconceito, somado às agressões físicas e emocionais, deixa marcas profundas nas pessoas. A expectativa de vida das travestis e das mulheres trans é de 35 anos. A média nacional, segundo dados do IBGE é de 75,5 anos. O tema é objeto de estudo do psicólogo Pedro Sammarco, autor do livro "Travestis envelhecem?".

Os trans sofrem incompreensão e rejeição de onde eles mais precisavam de apoio, que é no âmbito familiar. Ikemoto, (2017, p. 1) informa que:

Embora a palavra casa seja sinônimo de segurança e conforto para muitas pessoas, grande parte da população trans enfrenta violência e humilhação justamente onde deveria encontrar acolhimento. Muitas das histórias narradas por travestis e transexuais brasileiros se iniciam de forma parecida: com a incompreensão e a rejeição familiar, que os lançam em um trajeto de exclusão e incerteza.

O preconceito e a falta de conhecimento fazem com que uma a cada seis agressões a transgêneros registradas no Brasil sejam de algum parente próximo. Ikemoto, (2017, p. 2) menciona:

Pelo Disque 100, canal para denúncias de violações contra essa parcela da sociedade, mantido pela Secretaria de 
Direitos Humanos (SDH), foram registradas 1.792 agressões contra LGBTs em 2014. Um em cada seis desses crimes foi cometido por parentes das vítimas - 79 pelos pais; 74 por irmãos; 70 por companheiros, tios ou cunhados; e 57 por outros familiares.

Muitas histórias narradas pelas travestis e transexuais começam da mesma forma, a humilhação e rejeição dentro de casa, gerando incertezas, questionamentos sobre a vida e a própria existência, levando a automutilação ou até mesmo ao suicídio, que não é raro, nem tão pouco uma surpresa dentro da história da população transgênero. As relações familiares (trans x família) mais complexas são aquelas em que existe uma religião por parte desses entes da família, pois eles acreditam, desumanamente, que ser transgênero é "coisa do demônio" ou uma patologia, o que os levam a querer levar o filho ou filha para algum tipo de tratamento.

Outro agravante é a influência religiosa, pois contribuem para a continuidade do preconceito e não discutem acerca do gênero, muitos menos sobre o respeito ao próximo independente de quem ele seja, de como ele se reconhece, com qual gênero se relaciona e sobre sua fé. Se isso não é discutido e é ignorado ou até mesmo criticado, digamos que essa "religião" propaga o ódio entre os seres humanos ou até mesmo uma hierarquia entre eles, no qual não merece a atenção dos mais entendidos, humanamente falando.

Para não falarmos somente das histórias tristes de quem fez a transição, também podemos ver alguns relatos na internet e através de conversas com alguns deles, sobre as histórias de trans que tiveram o final feliz, com o apoio da família, que se preocuparam o tempo todo com sua saúde, com o respeito que devem propagar e com a aceitação de fato, essas histórias infelizmente são raras entre essa população, mas existem.

5. A dignidade da pessoa humana dentro do contexto dos transgêneros

Os direitos humanos são de suma importância para viabilizar uma boa convivência entre todos os seres humanos e para a formação do nosso Estado Democrático de Direito, é nesse contexto que entra o princípio constitucional basilar, no qual orienta todos os outros, o princípio da dignidade da pessoa humana. A dignidade da pessoa humana é garantida para todos os seres humanos, sem ressalva. O art. $1^{\circ}$ da CRFB (Constituição da República Federativa do Brasil de 1988) disciplina in verbis:

Art. $1^{\circ}$ A República Federativa do Brasil, formada pela união indissolúvel dos Estados e Municípios e do Distrito Federal, constitui-se em Estado Democrático de Direito e tem como fundamentos:

$[\ldots]$

III - a dignidade da pessoa humana. (BRASIL, 1988, p. 1). 
Logo em seguida, disciplina o art. $3^{\circ}$ da CRFB (Constituição da República Federativa do Brasil de 1988) nestes termos:

Art. $3^{\circ}$ Constituem objetivos fundamentais da República Federativa do Brasil:

$[\ldots]$

IV - promover o bem de todos, sem preconceitos de origem, raça, sexo, cor, idade e quaisquer outras formas de discriminação. (BRASIL, 1988, p. 1).

A dignidade da pessoa humana adentra no direito como um princípio jurídico-constitucional, tendo como principal escopo garantir os direitos fundamentais de um ser humano, podendo ser direitos políticos ou morais. Qualquer lei que afete a dignidade da pessoa humana será nula, pois ela é inviolável.

Barroso (2018, p. 152) informa que:

Após a Segunda Grande Guerra, a dignidade tornou-se um dos grandes consensos éticos do mundo ocidental, materializado em declarações de direitos, convenções internacionais e constituições. Apesar do grande apelo moral e espiritual da expressão, sua grande vagueza tem feito com que ela funcione, em extensa medida, como um espelho: cada um projeta nela a sua própria imagem, os seus valores e convicções. Isso tem feito com que a ideia de dignidade seja frequentemente invocada pelos dois lados do litígio, quando estejam em disputa questões moralmente controvertidas.

A Constituição Federal elucida, claramente, que as pessoas devem buscar a felicidade, independentemente de como se reconhecem com sua identidade, gênero e orientação sexual, é um direito que não deve ser violado, pois os transgêneros não podem mais ficar submetidos à margem da sociedade devido a cultura preconceituosa que foi construída com o passar dos anos.

\section{Resultado das entrevistas ${ }^{1}$}

As três entrevistas feitas nem sempre tiveram similaridade, mas também revelaram momentos análogos na história de vida dos transgêneros. Partindo desse pressuposto, a interpretação dos dados fornecidos exigiu uma análise minuciosa, tanto no que diz respeito às partes iguais como também nas diferenças. Os nomes utilizados abaixo são fictícios, por questões éticas, mas, se houver necessidade, o questionário da pesquisa tem todas as informações possíveis.

Entrevistas realizadas pelos autores (2019). 


\section{Caracterização dos entrevistados}

Primeiro entrevistado: Pedro $S$.

Homem trans, 25 anos, cursando ensino superior em Direito, mora em Salvador - Bahia, seu gênero biológico é o feminino e o gênero psicológico é o masculino.

Pedro conta que antes do seu processo de transição sentia que algo faltava, porém não conseguia perceber o que era exatamente, não gostava de fotos, não se sentia bem com as vestimentas e nem com o cabelo, nada nunca estava bom. Havia momentos em que se sentia bem e bonito, mas era raro.

Fala que teve uma vida normal e quando todas essas questões de transição chegaram à cabeça, ficou surpreendido, pois tudo passou a ter sentido naquele momento que compreendeu sua identidade de gênero.

O procedimento de alteração dos seus documentos de identificação foi feito após a Ação Direta de Inconstitucionalidade n. 4.275, diretamente no cartório. A decisão teve um impacto positivo na sua vida, porém enfrentou burocracias no momento da apresentação dos documentos que são exigidos para fazer a modificação.

A maior burocracia enfrentada para realizar a alteração dos documentos foi à solicitação cartorária de que se dirigisse até o seu cartório de origem do registro, localizado em Ilhéus, sendo que ele reside em Salvador. Em setembro de 2018 entrou com o pedido na comarca indicada e só obteve êxito na demanda em abril de 2019, sete meses de uma longa espera.

Segundo Pedro, foram muitas as vantagens obtidas após a alteração dos documentos, pois foi o fim dos constrangimentos e exposições para acessar a faculdade, festas, o trabalho e demais locais que exigem o documento de identificação.

O momento exato que sentiu vontade de realizar a alteração dos documentos foi quando começou a fase de transição/adequação, esse sentimento fluiu pela necessidade de ter o seu prenome e gênero reconhecido.

Pedro faz um relato emocionante e muito raro, que foi sobre o apoio familiar, conta que não enfrentou nenhum conflito, sempre teve o apoio que precisava. Destaca que se sentiu privilegiado, porque a maioria dos trans passa por sérios conflitos dentro de casa.

No que diz respeito aos constrangimentos enfrentados o pior foi o acesso à saúde, pois ele tinha plano e não permitiram usar o nome social. Conta que naquela época ainda não tinha mudado todos os documentos, então se sentia transtornado quando havia necessidade de ir ao médico. Hoje em dia isso não acontece mais, pois Pedro faz todo o acompanhamento pelo CEDAP, que é um ambulatório que acolhe a população transgênero. 
Nas relações de trabalho teve algumas dificuldades quando estava passando pela transição, mas isso não ocorre mais. Já nas relações sociais, entre amigos, teve todo o apoio necessário, inclusive considera como uma segunda família.

O entrevistado falou um pouco sobre a importância do princípio da dignidade da pessoa humana. A seu ver, só funciona em tese, no sentido de colocá-lo em igualdade com os demais sujeitos da sociedade, haja vista que na prática isso não ocorre, mesmo tendo alterado o prenome e gênero, ainda haverá situações que continuarão ocorrendo pelo resto da vida.

Segundo entrevistado: Júlio $V$.

Homem trans, nascido no dia $1^{\circ}$ de outubro de 1995, 23 anos, cursando ensino superior em direito, reside em Salvador - Bahia.

Ao ser questionado sobre o seu gênero psicológico e gênero biológico Júlio respondeu que: "Discordo do termo gênero biológico e gênero psicológico. Acho melhor dizer o gênero designado no nascimento dada a cultura de designar gênero pela genitália é feminino, mas meu gênero é masculino desde o nascimento."

Sobre a sua vida antes da adequação conforme a identidade de gênero relata que sempre se viu como homem e agiu como tal, na infância o chamavam de "moleque macho", mas hoje tem consciência que as pessoas não tinham conhecimento da transexualidade e nem acesso a informações sobre a transição de gênero.

O entrevistado ajuizou uma ação na tentativa de alterar todos os documentos, mas o processo ficou parado durante seis meses, sem nenhum retorno. No meio do trâmite processual a decisão do Supremo Tribunal Federal na Ação Direta de Inconstitucionalidade n. 4.275 foi julgada procedente, então ele solicitou a desistência da causa judicial e foi até o cartório de origem solicitar a modificação dos documentos.

Sobre a importância da procedência da ADI n. 4.275, relata que foi julgada em momento tardio, pois deu início a sua transição em setembro de 2016 e só conseguiu retificar os documentos em julho de 2018, pois fez a solicitação no cartório após a decisão supramencionada, que foi em maio de 2018, mas a retificação só foi concluída em julho de 2018, dois meses tramitando na área administrativa.

Júlio conta que foi o primeiro transgênero com o registro retificado na cidade de Santo Estevão e que apesar de ter enfrentado burocracias com as documentações conseguiu fazer as retificações necessárias.

Com a sua nova documentação consegue ter tranquilidade e notoriamente conseguiu o respeito dos demais, pois não precisa mais explicar que é um transgênero, tendo em vista que os documentos novos já condizem com sua aparência física, ficou livre da exposição e dos constrangimentos. 
Ao ser questionado se houve conflitos no âmbito familiar, informou que: "Não, minha mãe foi a primeira a me apoiar a iniciar a transição. Por ter me assumido cedo, moldei e preparei minha família para a diversidade. Se tornaram defensores e ativista da causa, me defendem com unhas e dentes. Houve um pedido de minha mãe para manter o nome parecido com meu de nascimento, mas foram detalhes que contornei. Mas costumo dizer que minha família transicionou comigo, eles também mudaram, evoluíram, entenderam e sempre buscam entender estudar a diversidade de gênero não apenas pra me defender, mas para desconstruir ainda mais o conceito de família tradicional. Me sinto orgulhoso em ter construído minha família a ponto de serem como são hoje. A construção refletiu em mim e em todos arredores, pois quedou-se o preconceito e prevaleceu o amor, o respeito as diferenças todas, principalmente de gênero e sexualidade".

Outro relato do entrevistado que merece destaque, é sobre os constrangimentos que mais lhe marcaram, seja no acesso à justiça, à saúde e/ou educação: "A saúde até hoje passo por constrangimento, pois sou dependente do plano de minha avó ao qual ainda não está retificado o nome. Uso o nome de nascimento ainda, porém sempre pontuo uso do nome social nos atendimentos. Tenho saúde fraca ando muito em hospital, então uso bastante do plano e sempre tenho que explicar a transexualidade nas marcações de consulta e etc. Mas pelo SUS quando transicionei já tinha portaria garantindo uso do nome social em atendimento público, hospital, postos, então minha carteira do SUS já foi feita com nome social. Uma vez passei mal no interior e não respeitaram meu nome social, amigos enfermeiros tomaram a frente em minha defesa, tive que me expor".

Nas relações empregatícias ainda tem muitas dificuldades, é o único momento que esconde sua transexualidade por medo de perder o emprego e não ter formas para sobreviver. Notoriamente emocionado, conta que não sabe como as pessoas podem reagir diante dessa informação e acredita que pode até perder uma oportunidade futura. Já nas relações sociais de amizade ele é muito feliz, sempre teve o apoio de todos os amigos.

Júlio fala um pouco sobre a importância da dignidade da pessoa humana dentro do contexto vivenciado por ele: "A dignidade da pessoa humana é um princípio importantíssimo que temos garantido constitucionalmente. É muito amplo e justamente essa amplitude que permite que as minorias alcancem lugares antes intocáveis. Se tivemos toda evolução no nosso país nos últimos anos foi devido ao reconhecimento da dignidade da pessoa humana como crucial para melhorar as relações sociais na sociedade e ao mesmo tempo se estamos regredindo no atual governo é justamente por não valorização de tal princípio como essencial para reger a sociedade e suas relações". 
Terceiro entrevistado: Lucas $R$.

Homem trans, 23 anos, cursando ensino superior, reside em Salvador Bahia, seu gênero biológico é o feminino e o psicológico é masculino.

Lucas conta que passou por momentos de choque, porque os pais o levavam para a igreja, em busca de uma "solução" para sua transexualidade e que na sua adolescência era tratado como se fosse uma mulher lésbica.

Relata que estava sentindo alguma coisa acontecendo de diferente, mas não sabia de fato o que era. No $5^{\circ}$ semestre da faculdade em meio a um trabalho com recorte sobre violência contra a mulher trans foi que ele começou a compreender e pesquisar sobre a identidade de gênero.

Nesse momento da entrevista, ele fica emocionado ao relatar como conseguiu se entender e transmitir para todos quem ele realmente era. A segunda parte ocorreu em meio à apresentação do seminário sobre as mulheres trans em situação de violência, foi quando resolveu falar: "a partir de hoje eu quero que todos me chamem de Lucas". Rindo do contexto vivenciado, ele conta que não sabia o que ia acontecer dali para frente, nem como as pessoas iam lhe tratar, mas fez o que o seu coração mandou. Lucas também conta que tinha uma namorada, mas depois dessa situação o relacionamento foi acabando aos poucos e chegaram ao consenso do término.

A alteração do seu prenome e gênero tá sendo realizada pela via administrativa, solicitou a retificação através de um mutirão feito pela Defensoria Pública. A alteração ainda não foi feita, pois os servidores cartorários estão impondo dificuldades para realizar o procedimento, falam que precisa de uma certidão atualizada para poder dar entrada e que tem que ser mediante pagamento da averbação, pois lá não tem isenção.

$\mathrm{O}$ entrevistado informa que ainda chegou a pagar pela averbação, mas no dia da retirada dos documentos os servidores não liberaram, sustentando que ele precisaria levar uma certidão de nascimento atualizada.

Revoltado com a situação que vem ocorrendo, comentou que não são todas as pessoas que abraçam a causa e que estão dispostos a contribuir, mas, ainda assim, fala humildemente que apesar do que vem acontecendo, teve muita sorte, pois conseguiu utilizar seu nome social no trabalho e no ticket alimentação.

Resolveu fazer a alteração nos documentos desde que "assumiu" para seu âmbito social a identidade de gênero e foi a partir daí que começou os conflitos no âmbito familiar, inclusive já se passaram dois anos que saiu de casa, pois seus pais estavam mantendo o controle sobre a sua vida, tomaram a chave e ordenavam que ele só podia ficar em casa e na faculdade. 
Dentro de todos os contextos vividos, a parte mais dolorida (até para quem ouve) foi o relato da ameaça que a mãe fez, dizendo que ia jogar ácido nele e que ia se suicidar, mas antes ia escrever uma carta dizendo que foi o próprio filho que a matou.

Ainda dentro do contexto familiar, Lucas fala que o pai era o mais aberto para dialogar, então foi a primeira pessoa que contou sobre o que estava acontecendo com ele. O pai o recebeu falando que já sabia e até tinha procurado saber sobre os procedimentos que precisaria fazer.

Essa boa relação entre pai e filho durou pouco tempo, pois o seu pai contou para a sua mãe, que sempre foi intolerante e não o compreendia, acabando ali com a confiança existente. Em meio a tudo isso, seu pai que antes se mostrava parceiro falou que jamais ia deixar de ser pela mulher (sua mãe). Bem triste conta que nunca houve uma tentativa de mediação familiar, pois ainda tinha seu irmão gay que não lhe deu nenhum apoio e acabou virando inimigo.

Dentre os constrangimentos enfrentados, conta sobre quando foi ser atendido em um hospital por uma médica e precisou tirar a roupa, relata que ela parecia uma profissional despreparada para lidar com a diversidade, pois seu nome informado na ficha era o social e ao tirar a roupa tinha o seu sexo biológico. A referida médica começou a questioná-lo com quem ele mantinha relações, se era homem ou mulher, totalmente incabível.

Nas relações empregatícias, teve dificuldade com seu supervisor que é gay e o humilhava o tempo todo por ser homem trans. Não passou por situações fáceis também nas relações de amizade, pois tudo que estava acontecendo na sua vida contribuiu para que se afastasse de todos como uma forma de proteção.

Ao ser questionado sobre a dignidade da pessoa humana dentro do contexto vivenciado, informa que não funciona como é na teoria e que se fosse, seria maravilhosa, ainda comenta que as pessoas não vão enxergá-lo apenas como um ser humano e segurarlhe a mão em todas as situações precisas, pois existe um nível de hierarquia entre essas relações.

\section{Considerações finais}

A procedência do julgamento no Supremo Tribunal Federal na Ação Direta de Inconstitucionalidade n. 4.275 veio para dar interpretação conforme a Constituição da República Federativa do Brasil de 1988 e o Pacto de São José da Costa Rica ao art. 58 da Lei n. 6.015/73.

Após o estudo sobre as histórias de vida percebe-se que a referida decisão impactou de diversas formas na vida dos transgêneros, o primeiro impacto é o positivo, pois agora eles já podem ir diretamente ao cartório solicitar a alteração do prenome e 
gênero sem a obrigatoriedade de ter feito a cirurgia de transgenitalização. Com isso, houve uma ressignificação da dignidade da pessoa humana e a reafirmação de direitos já existentes, tendo em vista que os constrangimentos diminuíram ao acessar locais que exigem o documento de identificação, sendo esse o fator principal relatado por eles.

O segundo impacto é o negativo, sendo que conforme as entrevistas feitas essa decisão foi julgada procedente em momento tardio, pois algumas pessoas já estavam a algum tempo aguardando a decisão do judiciário. Outro impacto negativo que foi relatado é a alegação dos funcionários do cartório sobre dúvida procedimental, ou seja, alegam que não sabem como proceder para fazer essa alteração. Nessa parte, um dos entrevistados informa que a alegação da dúvida procedimental é mais uma desculpa para cobrir a transfobia institucional.

Conclui-se que houve um avanço na história do Brasil com a Ação Direta de Inconstitucionalidade n. 4.275, pois apesar dos impactos negativos mencionados é perceptível que já estamos um passo à frente da desconstrução da cultura transfóbica. De suma importância destacar que a violência é algo muito presente na vida dessas pessoas e que essa evolução não acaba com a violência, mas diminui de forma significativa.

Salvador, setembro de 2020 .

\section{Referências}

ARPINI, Naiara. Psicóloga explica diferença entre identidade de gênero e orientação sexual. Portal G1, Espírito Santo, 13 ago. 2017. Disponível em: https:/g1.globo.com/espirito-santo/noticia/ psicologa-explica-diferenca-entre-identidade-de-genero-e-orientacao-sexual.ghtml. Acesso em: 16 maio 2019.

BARROSO, Luís Roberto. O constitucionalismo democrático no Brasil: crônica de um sucesso imprevisto. [S. l.], 2018. Disponível em: http://www.luisrobertobarroso.com.br/wp-content/ uploads/2012/12/O-constitucionalismo-democratico-no-Brasil.pdf. Acesso em: 20 maio 2019.

BATISTA, Francesca Alves. O transgênero segundo o STF. Revista Jus Navegandi, Teresina, ano 24, n. 5.758, 7 abr. 2019. Disponível em: https:/jus.com.br/artigos/73069/o-transgenero-segundoo-stf. Acesso em: 15 maio 2019.

BORTONI, Larissa. Expectativa de vida de transexuais é de 35 anos, metade da média nacional. Portal do Senado Federal, Brasília, DF, 20 jun. 2017. Senado Notícias. Disponível em: https:// www12.senado.leg.br/noticias/especiais/especial-cidadania/expectativa-de-vida-de-transexuais-ede-35-anos-metade-da-media-nacional/expectativa-de-vida-de-transexuais-e-de-35-anos-metadeda-media-nacional. Acesso em: 4 abr. 2019. 
BRASIL. [Constituição (1988)]. Constituição da República Federativa do Brasil de 1988. Brasília, DF: Senado, 1988. Disponível em: http://www.planalto.gov.br/ccivil_03/constituicao/constituicao. htm. Acesso em: 22 mar. 2019.

BRASIL. Supremo Tribunal Federal. ADI 4275. Relator Ministro Marco Aurélio. Disponível em: http://portal.stf.jus.br/processos/detalhe.asp?incidente=2691371. Acesso em: 1 mar. 2018.

CUNHA, Thaís. Rotina de exclusão e violência. Correio Braziliense, Brasília, DF, 2017. Disponível em: http://especiais.correiobraziliense.com.br/brasil-lidera-ranking-mundial-de-assassinatos-detransexuais. Acesso em: 30 mar. 2019.

DIAS, Surenã. Transexualidade deixa de ser considerada transtorno mental pela OMS. Portal BOL, São Paulo, 21, maio 2019. Observatório G. Disponível em: https://observatoriog.bol.uol.com.br/ noticias/2019/05/transexualidade-deixa-de-ser-considerada-transtorno-mental-pela-oms. Acesso em: 22 maio 2019.

IKEMOTO, Luisa. Em vez de acolhimento, rejeição. Correio Braziliense, Brasília, DF, 2017. Disponível em: http://especiais.correiobraziliense.com.br/transexuais-e-travestis-sofrem-violenciadentro-de-casa. Acesso em: 30 mar. 2019.

JESUS, Jaqueline Gomes de. Orientações sobre identidade de gênero: conceitos e termos. 2. ed. Brasília: [s. n.], 2012.

LEITE, Hellen. A saúde negada. Correio Braziliense, Brasília, DF, 2017a. Disponível em: http:// especiais.correiobraziliense.com.br/receber-cuidados-medicos-e-desafio-para-transexuais. Acesso em: 30 mar. 2019.

LEITE, Hellen. Que T é esse? Correio Braziliense, Brasília, DF, 2017b. Disponível em: http:// especiais.correiobraziliense.com.br/transexual-travesti-drag-queen-qual-e-a-diferenca. Acesso em: 30 mar. 2019.

NERY, João W. Viagem solitária: memórias de um transexual 30 anos depois. São Paulo: Leya, 2011.

RAMSEY, Gerald. Transexuais: perguntas e respostas. São Paulo: Summus/GLS, 1988. 